\title{
Leading twin in breech presentation, is routine caesarean section necessary?
}

\author{
Lopamudra B. John*, Reddi Rani P., Seetesh Ghose
}

Department of Gynaecology and Obstetrics, Mahatma Gandhi Medical College and Research Institute, Pondicherry, India

Received: 25 November 2015

Revised: 09 January 2016

Accepted: 16 January 2016

\section{*Correspondence:}

Dr. Lopamudra B. John,

E-mail: drlopamdpondy@yahoo.com

Copyright: () the author(s), publisher and licensee Medip Academy. This is an open-access article distributed under the terms of the Creative Commons Attribution Non-Commercial License, which permits unrestricted non-commercial use, distribution, and reproduction in any medium, provided the original work is properly cited.

\begin{abstract}
Background: Multiple gestations and Caesarean delivery are both showing a rising trend worldwide. One major cause for Caesarean section in twin gestations is leading twin in breech presentation. This study is to find out whether vaginal delivery is an option in such cases.

Methods: Out of 66 twin deliveries, 27 cases were studied with one twin in breech presentation after excluding the previous LSCS cases. Maternal parameter studied was section rates in primi and multi gravida respectively. Neonatal parameters studied were birth weight and Apgar scores of breech twins and after weight wise distribution of babies into 4 groups the morbidity of those born vaginally were compared to those delivered by Caesarean section.

Results: Twin deliveries constituted $2.7 \%$ of total deliveries in one year and combinations of breech with 2 nd foetus in breech, cephalic and transverse presentations were 16.8, 9 and 3\% respectively. Out of 19 first breech twins, 11 were in primigravida who underwent LSCS and 5 in multigravida of which $60 \%$ underwent LSCS. So $40.6 \%$ of primary LSCS were due to first twin in breech. Out of 19 2nd breech twins, 6 delivered vaginally. Irrespective of mode of delivery, morbidity was influenced by birth weight, where babies $<1.5 \mathrm{~kg}, 1.5-2 \mathrm{~kg}, 2.1-2.5 \mathrm{~kg}$ and $>2.5 \mathrm{~kg}$ required NICU care in 100, 64, 20 and $0 \%$ cases in the LSCS group compared to 100, 66.7,0 and0\% cases in the vaginal delivery group.

Conclusions: Vaginal delivery can be considered as an option for first twin breech specially in multigravida.
\end{abstract}

Keywords: Twins, Breech, Caesarean, Delivery

\section{INTRODUCTION}

The advent of induced ovulation and artificial reproductive techniques used for the treatment of infertility has led to worldwide increase in multiple births compared to natural conceptions. ${ }^{1}$ Also, the alarming rise of Caesarean section rates worldwide is a matter of concern and the choice is based on medical as well as social determinants. ${ }^{2}$ Several measures are being considered to reduce these rates. Compared to singleton pregnancies, twin gestations are expected to have a higher possibility of Caesarean delivery due to various causes mainly concern about the morbidity and mortality of the second twin. ${ }^{3}$ When the leading twin is in cephalic presentation, routine Caesarean section is not beneficial. ${ }^{4}$ However, one of the major causes of Caesarean section in twin gestations is nonvertex presentation of the leading twin. The Term Breech Trial results have led to delivery of term singleton breech babies by Caesarean section. ${ }^{5}$ There is no clear guideline regarding the preferred mode of delivery when the first twin is in breech presentation. This study is undertaken to find out the impact of breech first twin on the mode of delivery and whether vaginal delivery can be considered as an option. 


\section{METHODS}

This study was conducted in a tertiary care centre and all the 66 twin deliveries over a period of one year were taken into account. The inclusion criteria were twin gestations with first or second twin in breech presentation and more than 34 completed weeks of gestation which constituted of 27 cases. The cases of previous Caesarean section were excluded from the study. The maternal parameters noted were the Caesarean section rates in women with the first twin in breech presentation both in primi and multigravida. The neonatal parameters measured were birth weight and Apgar scores of both the first and second breech twin born by vaginal delivery as well as by Caesarean section. The babies with breech presentation were divided into two groups of vaginal delivery and Caesarean section and each group subdivided into babies weighing less than $1.5 \mathrm{~kg}, 1.5$ to 2 $\mathrm{kg}, 2.1$ to $2.5 \mathrm{~kg}$, and $2.6 \mathrm{~kg}$ and above. In these twin pregnancies, the morbidity of the babies born by assisted breech delivery and those born by Caesarean section were compared.

\section{RESULTS}

Table 1: Combinations of presentation in twin gestations.

\begin{tabular}{|llll|}
\hline Twin 1 & Twin 2 & No. & $\%$ \\
\hline Cephalic & Cephalic & 35 & 53 \\
\hline Cephalic & Breech & 7 & 10.7 \\
\hline Cephalic & Transverse & 2 & 3 \\
\hline Breech & Cephalic & 6 & 9 \\
\hline Breech & Breech & 11 & 16.8 \\
\hline Breech & Transverse & 2 & 3 \\
\hline Transverse & Cephalic & 1 & 1.5 \\
\hline Transverse & Breech & 1 & 1.5 \\
\hline Transverse & Transverse & 1 & 1.5 \\
\hline
\end{tabular}

Over a period of one year there were 66 twin deliveries which constituted $2.7 \%$ of the total number of deliveries in the institution. Out of these, 32 cases underwent primary Caesarean section which is $48.5 \%$. Regarding the presentations of twins, the commonest combination was both cephalic in $53 \%$ cases followed by both breech in $16.8 \%$ cases. The other combinations were first in breech and second in cephalic in $9 \%$ cases and first in breech and second in transverse in 3\% cases (Table 1). A total number of 19 cases had first foetus in breech presentation out of which 11 were in primigravida, 5 in multigravida and another 3 in multigravida with previous Caesarean section. All the primigravida with first twin breech underwent Caesarean section. $60 \%$ of the multigravida with previous normal delivery also underwent Caesarean section due to breech first twin. So $40.6 \%$ of the primary Caesarean sections in twin gestations were due to leading twin in breech presentation (Table 2). There were a total of 19 babies in breech presentation in the second twin. Out of this, 6 babies delivered by vaginal assisted breech delivery and the rest 13 delivered by Caesarean section (Table 3).

Table 2: Mode of delivery with first twin breech.

\begin{tabular}{|lll|l|}
\hline & No. & $\begin{array}{l}\text { No. Underwent } \\
\text { LSCS }\end{array}$ & $\%$ \\
\hline Total Twin 1 breech & 19 & 17 & 89.5 \\
\hline Primi & 11 & 11 & 100 \\
\hline Multi & 5 & 3 & 60 \\
\hline Multi prev LSCS & 3 & 3 & 100 \\
\hline
\end{tabular}

Table 3: Mode of delivery in twin 1 and twin 2 in breech presentation.

\begin{tabular}{|lllll|}
\hline Breech & No. & SVD & LSCS & \% LSCS \\
\hline Twin 1 & 19 & 2 & 17 & 89.5 \\
\hline Twin 2 & 19 & 6 & 13 & 68.4 \\
\hline
\end{tabular}

2 out of 19 babies in leading twin in breech presentation were delivered by assisted breech delivery and 6 out of 19 second twins in breech presentation were delivered vaginally. Both the leading breech twins delivered vaginally were in multigravida. 4 out of the 6 second breech twin delivered vaginally were also in multigravida. Regarding the morbidity of these breech babies the major factor determining the need for neonatal intensive care unit was the birth weight rather than the mode of delivery. All babies less than $1.5 \mathrm{~kg}$ required NICU care irrespective of the mode of delivery whereas all babies above $2.5 \mathrm{~kg}$ didn't require it. Babies with weight between 1.5 to $2 \mathrm{~kg}$ required NICU in $66.7 \%$ and $64 \%$ of the cases in the vaginal and Caesarean delivery groups respectively. The babies weighing 2.1 to $2.5 \mathrm{~kg}$ required NICU in $20 \%$ cases in the Caesarean group (Table 4).

Table 4: Correlation of mode of delivery, birth weight and NICU admission.

\begin{tabular}{|llllll|}
$\begin{array}{l}\text { Weight } \\
(\mathrm{kg})\end{array}$ & $\begin{array}{l}\text { Total } \\
\text { No. }\end{array}$ & $\begin{array}{l}\text { Assisted } \\
\text { breech } \\
\text { delivery }\end{array}$ & $\begin{array}{l}\% \\
\text { NICU }\end{array}$ & LSCS & $\begin{array}{l}\% \\
\text { NICU }\end{array}$ \\
\hline$<1.5$ & 3 & 1 & 100 & 2 & 100 \\
\hline $1.5-2$ & 14 & 3 & 66.7 & 11 & 64 \\
\hline $2-2.5$ & 18 & 3 & 0 & 15 & 20 \\
\hline$>2.5$ & 3 & 1 & 0 & 2 & 0 \\
\hline
\end{tabular}

\section{DISCUSSION}

The preferred mode of delivery in twin gestations where the leading twin is in breech presentation is an area of controversy. The various clinical practice guidelines do not address this issue in a definitive manner. Regarding the incidence of first twin in breech presentation, in this study $28 \%$ cases presented as such which is similar to the study conducted by Nasser et al where it was $25 \%{ }^{6}$ 
Following the report of Term Breech Trial by Hannah et al here there was a significant reduction in neonatal mortality and morbidity in the planned Caesarean section group compared to the planned vaginal delivery group, the results has been extrapolated to twin gestations with first twin in breech presentation and planned Caesarean has been adopted to be the preferred mode of delivery in most centres. ${ }^{5}$ However various studies have concluded that vaginal delivery is an option in such cases. Essel et al compared the outcome of 35 breech-breech and 6 breechtransverse twins delivered vaginally with 25 breechbreech and 2 breech-transverse twins delivered by Caesarean section for the neonatal outcome and noted no significant difference in morbidity. ${ }^{7}$ In a retrospective study by Sentilhes et al, 124 twin pairs with first twin breech were planned for vaginal delivery. 52\% was delivered by Caesarean section and $48 \%$ had a vaginal delivery. The neonatal outcome was equal in both the groups. ${ }^{8}$ Grisaru et al studied 71 twin pairs with first twin in breech presentation and selected 33 for vaginal delivery out of which $54.5 \%$ cases were successful. The neonatal outcome was similar in both the vaginal and Caesarean delivery groups. ${ }^{9}$ Similar result was obtained by the study conducted by Abu et al. ${ }^{10}$ Mode of delivery didn't have any significance in the neonatal outcome in the study by Blickstein et al when the vaginal delivery group was chosen according to criteria for singleton pregnancy. ${ }^{11}$ Roopnarinesingh et al in a similar study commented that in absence of uterine scar or footling presentation there is no reason to prohibit vaginal delivery in breech first twins. ${ }^{12}$ In this study the neonatal outcome was similar when compared between the two groups of breech babies undergoing assisted breech delivery and Caesarean section.

Gestational age and baby birth weight plays an important role in the neonatal outcome in twin gestations. Blickstein et al in their study concluded that rather than mode of delivery in breech twins mortality and morbidity were influenced more by birth weight. Depressed Apgar scores and morbidity were significantly higher when birth weight was less than $1.5 \mathrm{~kg}{ }^{13}$ In this study also though there was no mortality, NICU care was required in all breech babies less than $1.5 \mathrm{~kg}$ irrespective of the mode of delivery and requirement decreased with increasing birth weight.

Bourtembourg et al in their study found a significant relationship between parity and route of delivery. Vaginal breech delivery was successful in less than one third of nulligravida versus two third in multigravida. ${ }^{14}$ In this present study the two first breech twins who delivered vaginally were in multigravida. In the second breech twin who delivered vaginally two third cases were in multigravida.

Another matter of concern in breech first twins is the possibility of interlocking. Not much data is available in this aspect. Cohen et al found the incidence to be very low and commented that the possibility should be considered in case of undue prolongation of labour. ${ }^{15}$

\section{CONCLUSIONS}

In absence of guidelines for mode of delivery of first twin in breech presentation routine Caesarean section is being followed in most centres. To reduce the shooting Caesarean section rates and since baby weights in twin gestations are lesser than singletons, vaginal delivery may be offered in these cases. However the concerns for neonatal mortality and morbidity cannot be disregarded and so multigravida with previous vaginal delivery are the ideal candidates for this treatment option. The safety of it's use in primigravida requires to be proven by studies with large sample size.

Funding: No funding sources Conflict of interest: None declared

Ethical approval: The study was approved by the Institutional Ethics Committee

\section{REFERENCES}

1. Sunderam S, Kissin DM, Crawford SB, Folger SG, Jamieson DJ, Warner L. Assisted reproductive technology surveillance-United States 2012. MMWR Surveill Summ. 2014;64(6):1-29.

2. Scioscia M, Vimercati A, Cito L, Chironna E, Scattarella D, Selvaggi LE. Social determinants of the increasing caesarean section rate in Italy. Minerva Ginecol. 2008;60 (2):115-20.

3. Seelbach-Goebel B. Twin birth considering the current results of Twin Birth Study. Geburtshilfe Frauenheilkd. 2014;74(9):838-44.

4. Hofmeyer GJ, Hannah M, Lawrie TA. Planned caesarean section for term breech delivery. Cochrane Database Syst Rev. 2015;7:CD000166.

5. Hannah ME, Hannah WJ, Hewson SA, Hodnett ED, Saigal S, Willian AR. Planned Caesarean versus planned vaginal birth for breech presentation at term: A randomised multicentre trial. Term Breech Trial Collaborative Group. Lancet. 2000;356(9239):137583.

6. Nassar AH, Mahrouf HH, Hobeika EM, Abd Essamad HM, Usta IM. Breech presenting twin A: Is vaginal delivery safe? J Perinat Med. 2004;32(6):470-4.

7. Essel JK, Opai-Tetteh ET. Is routine Caesarean section is necessary for breech-breech and breechtransverse twin gestations? S Afr Med J. 1996;86(9):1196-200.

8. Sentilhes L, Goffinet E, Talbot A, Diguet A, Verspyek E, Cabrol D, et al. Attempted vaginal versus planned Caesarean delivery in 195 breech first twin pregnancies. Acta Obstet Gynecol Scand. 2007;86(1):55-60.

9. Grisaru D , Fuchs S, Kupfermine MJ , Har-Toov J , Niv J , Lessing JB. Outcome of 306 twin deliveries 
according to first twin presentation and method of delivery. Am J Perinatol. 2000;17(6):303-7.

10. Abu- Heija AT, Ziadeh S, Obeidat A. Mode of delivery and perinatal results of the breech first twin. J Obstet Gynaecol. 1998;18(1):47-9.

11. Blickstein I, Weissman A, Ben - Hur A, Borenstein $\mathrm{R}$, Insler V. Vaginal delivery of breech-vertex twins. J Reprod Med. 1993;38(11):879-82.

12. Roopnarinesingh AJ, Sirjusingh A, Bassaw B, Roopnarinesingh S. Vaginal breech delivery and perinatall mortality in twins. J Obstet Gynaecol. 2002;22(3):291-3.

13. Blickstein I, Goldman RD, Kupferminc M. Delivery of breech first twins: A multicenter retrospective study. Obstet Gynaecol. 2000;95(1):37-42.
14. Bourtembourg A, Ramanah R, Jolly M, GannardPechin E, Becher P, Cossa S, et al. Twin delivery with the first twin in breech position. A study of 137 continuous cases. J Gynecol Obstet Biol Reprod (Paris). 2012;41(2):174-81.

15. Cohen M, Kohl SG, Rosenthal AH. Fetal interlocking complicating twin gestation. Am J Obstet Gynecol. 1965;91:407.

Cite this article as: Lopamudra BJ, Reddi RP, Ghose S. Leading twin in breech presentation, is routine caesarean section necessary? Int J Reprod Contracept Obstet Gynecol 2016;5:375-8. 